\title{
Mathematical model of the heat interaction between the metal matrix and the reinforcement phase during the production of Metal Matrix Composites
}

\author{
Daniela Todorova Spasoval and Krastin Krasimirov Yordanov ${ }^{2}$ \\ ${ }^{1}$ Technical University of Varna, Department of Materials Science and Technology, 1 Studentska Street, Varna 9010, Bulgaria \\ ${ }^{2}$ Technical University of Varna, Department of Heat Transfer, 1 Studentska Street, Varna 9010, Bulgaria \\ Corresponding author contact: danielatseabv.bg
}

\begin{abstract}
This present paper is relevant to the establishment on mathematical model of the heat interaction between the metal matrix (liquid phase- $\mathrm{Cu}$ ) and the reinforcement (solid- Fe) phase, during the production of the Metal Matrix Composites (MMCs) by the method of capillary molding. In this case a heat object is substituted with a mathematical model, drawn up and grounded to investigate the original behavior and properties, clarifies temperature fields in bodies.

The established simulation clarifies temperature fields and the causal liaison between the metal matrix and the reinforcement phase in the formation of the macro and microstructure at the time of production of MMCs. Casting process simulation is an approved method for the optimization of the methods of casting technology. The basic opportunities, ideology and structure of the software "MATLAB FEA" are introduced to simulate the casting technology. The possibilities of the product are illustrated by the results, obtained from a computer simulation by the technical process of the production of MMCs.
\end{abstract}

Keywords: mathematical model, MATLAB FEA, finite elements, casting process simulation, MMCs

\section{$1 \quad$ Introduction}

Casting is an old art, but with the development of mathematical modeling and computer simulation in the field of material science in recent years, it has already become a rapidly growing field of science. The advent of software products into global casting has become an integral part of the research and design activities, related to the refinement and optimization of foundry technologies, the creation of castings with high performance, the lowering of metal consumption, the realization of energy savings, also rapid and accurate and qualitative and quantitative diagnostics of a wide range of possible defects (Зиновиев В., 1989), (Марков К. 2014), (Шубина М. 2011).

The finite element method is a method that allows the numerical modeling of complex systems, provided that they are considered as continuous environments, and their dynamics is described by linear private differential equations: for example, the movement of a string fixed to one of its ends, the dynamics of fluid, the deformation of metal structures and others. One of the most famous software for such purposes is known as MATLAB FEA (Finite Element Analysis) (Марков И. ,2002), (Markov I. 2002).

In the present case, a mathematical model of thermal interaction has been created. Substitution of a thermal object with a mathematical model, compiled and grounded to study the behavior and properties of the two phases (liquid and solid) constituting the MMC (Daniel B.,1976), (Geslin P. 2012). In the theory of heat exchange, classes of inverse tasks play an increasingly important role and are often the only way to get results. They allow the determination of the causes of the heat process by a certain set of events (Klien S.,2015). In the problem under consideration, this theory can be applied to elucidate the temperature fields in the bodies and the causal liaison between the metal matrix and the reinforcement phase in the production of the MMCs.

The liquid metal is emerging as a new technology for the production of a topological complex of the metal-composite structures with an ultra-high interfacial area and other unique qualities, during the synthesis of complex relief MMCs by the capillary molding method (Радев P. 2010). This process is known as an empirically selective dissolution of the one component of a multicomponent solid alloy in a molten metal to obtain the desired structures (Xu Y. 2007). The present elaboration demonstrates the use of a 
mesoscale phase field to form a mathematical model, showing the result of the interaction and diffusion between the liquid and the solid phases during the production of MMCs by the capillary molding method. It's analyzed how these mechanisms interacted to obtain a wide variety of topographically unrelated and related structures.

\section{Exposition}

\subsection{Temperatures Determination During the Production of MMCs}

The research process was also accompanied by measuring the temperature in the working chamber. Based on these measurements, a mathematical model of interaction of the metal matrix and the reinforcement phase was created.

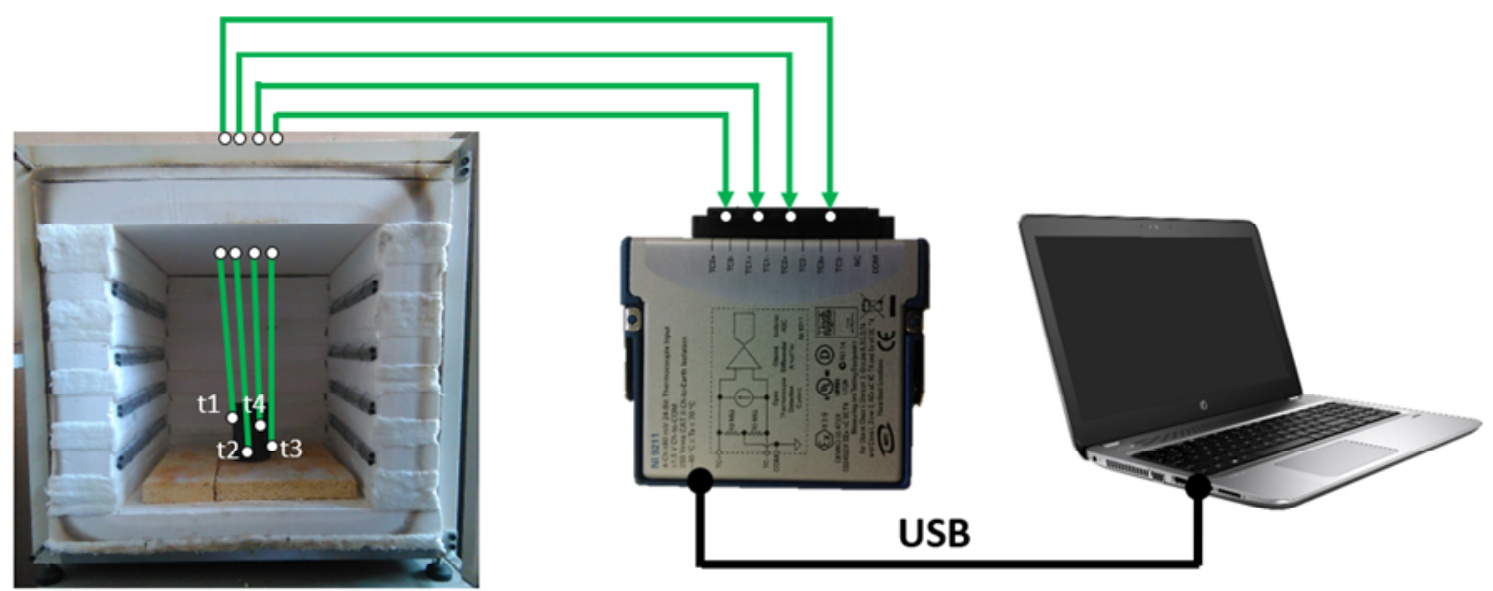

Fig. 1. Thermocouples position scheme

The solution of the problem is considered in a stationary mode, as is consistent temperature of phase transition from solid to liquid state and the behavior of the two phases relative to each other (the reinforcement phase $\mathrm{Fe}$ and the liquid $\mathrm{Cu}$ matrix). Before filling the casting mold with a metallic powder (containing $60 \% \mathrm{Fe}$ and $40 \% \mathrm{Cu}$ ), four thermocouples (chromium-aluminum $(\mathrm{NiCr}-\mathrm{NiAl})$ ) are attached to the heating device and the mold - one of them controlling and three observational (Fig. 1). Then the metallic powder is placed in the casting mold. Thermocouples measured simultaneously four temperatures on the surface of the mold cavity. In order the temperature measured to be accurate, the thermocouples are insulated with ceramic mixture and thermal wadding. Type $\mathrm{K}$ thermocouples are connected into the device, showing the temperature variation in 1 second. The device to which the thermocouples are connected is a four-channel analogue module NI-9211 of NATIONAL INSTRUMENTS that measures up to $\pm 80 \mathrm{mV}$. It has a high accuracy of $\pm 0.5 \%$, guaranteed by the manufacturer. The measured temperatures are registered, using a computer, in the form of graphs (Fig. 2). 
t1

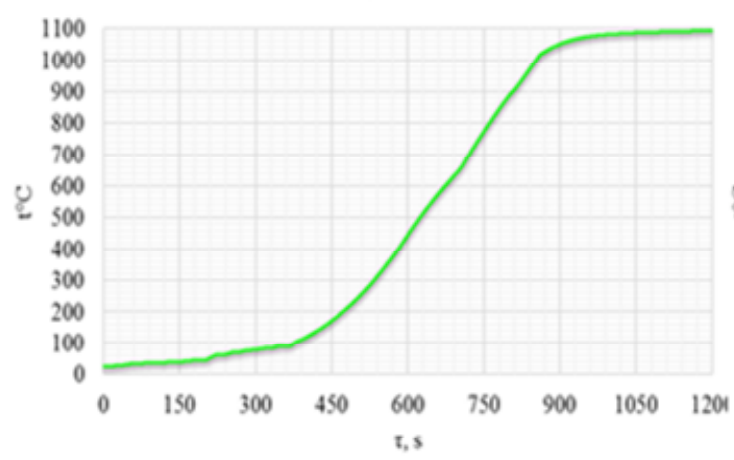

12

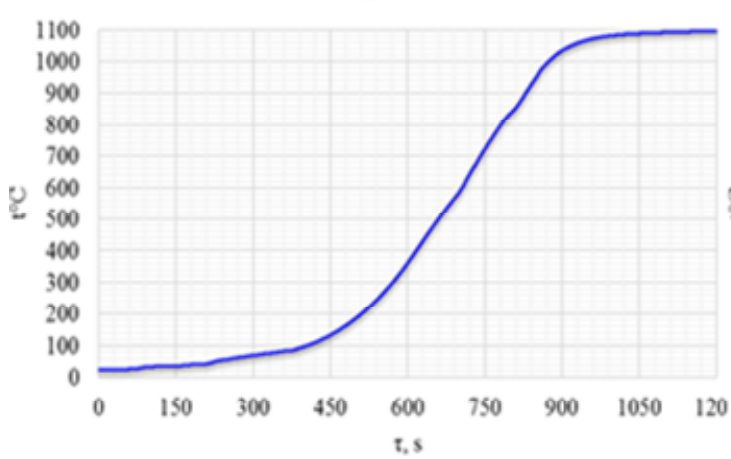

t3

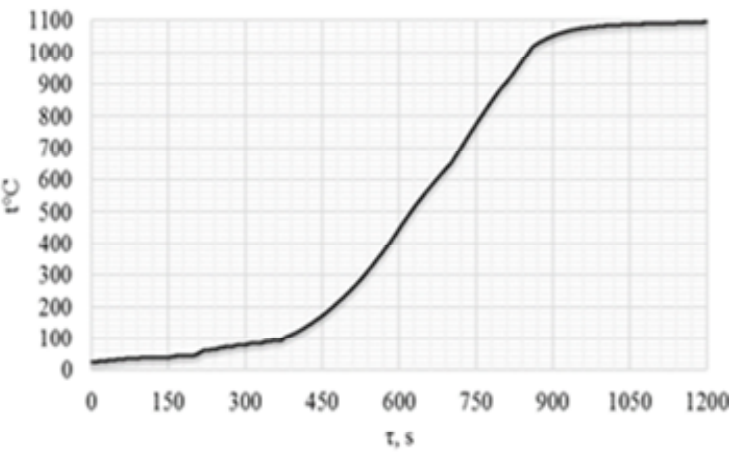

14

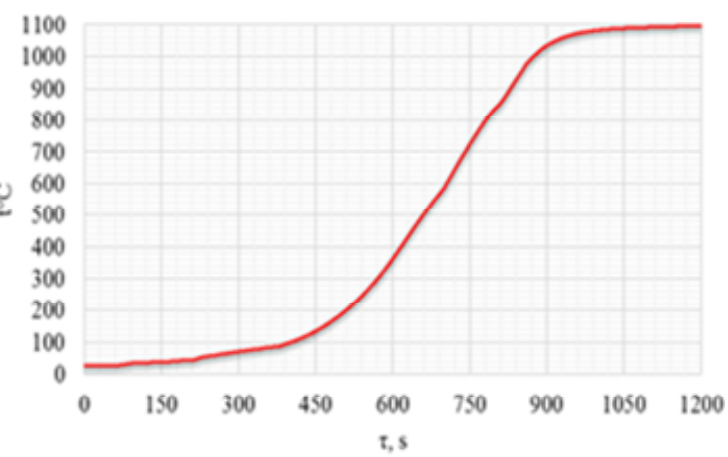

Fig. 2. Graphs of the measured temperatures - $\mathrm{t} 1$ - maximum temperature- $1094^{\circ} \mathrm{C}$; $\mathrm{t} 2$ - maximum temperature $-1095^{\circ} \mathrm{C}$; t3-maximum temperature $-1096{ }^{\circ} \mathrm{C}$; Graph t4- Maximum temperature- $1097{ }^{\circ} \mathrm{C}$

\subsection{General equations for creating a mathematical model}

The following equations were used to solve the problem:

General equations of fluid flow and heat conduction. For modeling equations in fluid flow and heat transfer processes, the equations of Navie-Stocks (or instantaneous equations) and the first principle of thermodynamics are adopted. The main differential equations are:

\section{Continuity equation:}

$$
\frac{\partial \rho}{\partial t}+\frac{\partial \rho u}{\partial x}+\frac{\partial \rho v}{\partial y}=0
$$

where: $t$ - time, $\mathrm{s} ; \rho$ - density, $\mathrm{kg} / \mathrm{m}^{3} ; u$ - velocity component in the direction $\mathrm{x}, \mathrm{m} / \mathrm{s} ; v$ - velocity component in the direction $\mathrm{y}, \mathrm{m} / \mathrm{s}$.

\section{Absolute, common, static and dynamic values}

Referring to the relative pressure $p_{\text {rel }}$, the absolute pressure $\left(p_{\text {absolute }}\right)$ is calculated as:

$$
p_{\text {absolute }}=p_{\text {rel }}+p_{\text {ref }}+\rho_{\text {ref }} \sum_{i} g_{i} X_{i}+\rho_{\text {ref }} \sum_{i} \omega_{i}^{2} X_{i}^{2}
$$

where: $p_{\text {rel }}$ - relative pressure, $\mathrm{Pa} ; p_{\text {ref }}$ - reference pressure, Pa; $g$ - gravitational acceleration, $\mathrm{m} / \mathrm{s}^{2} ; \omega-$ rotational speed, $\mathrm{rad} / \mathrm{s}$

For flow without gravitational or rotational forces, the relative pressure is manometric. 
General scalar transport equation:

The following equation describes the transport of a passive scalar function by incompressible fluid:

$$
\frac{\partial f}{\partial t}+u \frac{\partial f}{\partial x}+v \frac{\partial f}{\partial y}=\frac{\partial}{\partial x}\left[D \frac{\partial f}{\partial x}\right]+\frac{\partial}{\partial y}\left[D \frac{\partial f}{\partial y}\right]
$$

where: $\mathrm{D}$ - diffusion, $\mathrm{m}^{2} / \mathrm{s} ; f$ - passive scalar.

After simplifying the transport equation $(\Phi)$ as is the case, it yields the following form:

$$
\frac{\partial \rho V_{j} \Phi}{\partial x_{j}}+\frac{\partial}{\partial x_{j}}\left(\Gamma \frac{\partial \Phi}{\partial x_{j}}\right)=0
$$

where: $V_{j}$ - velocity vector.

\subsection{The task solution}

Geometry and mesh elements. The object's geometry is a model of a complex relief MMC composed of $60 \% \mathrm{Fe}$ and $40 \% \mathrm{Cu}$. The geometry of the composite is simplified to a cylindrical shape (Fig. 3. a).

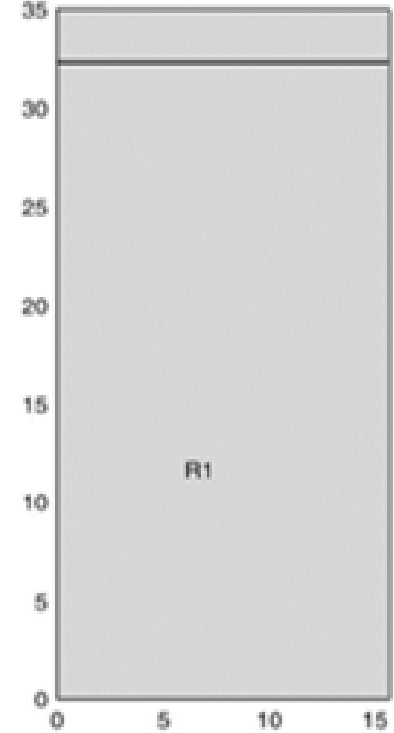

a)

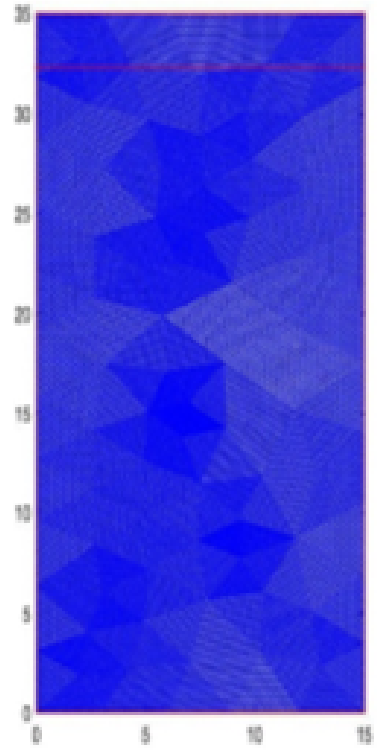

b)

Fig. 3. Geometry a) and discretization b) of the investigated object

Each mesh element is consisting of iron or copper particles, developed by the "MATLAB FEA" software product with the equations, described above. Discretization of the finite elements is shown on Fig. 3. b), represented in a x-y coordinate system. The discretization object is composed of triangular finite elements, such as: number of nodes-18809, number of mesh elements 37120 . The mesh grading factor is $0,0002 \mathrm{~mm}$. The boundary conditions of the object, shown on Fig. 4 are temperature (T), pressure $(\mathrm{P})$ and diffusion coefficient (D), assigned to the boundary lines of the figure. The values of the boundary conditions are $\mathrm{T}=1150^{\circ} \mathrm{C}, \mathrm{P}=95000 \mathrm{~Pa}$ and $\mathrm{D}=7,8 \times 10^{-16} \mathrm{~m}^{2} / \mathrm{s}$. 


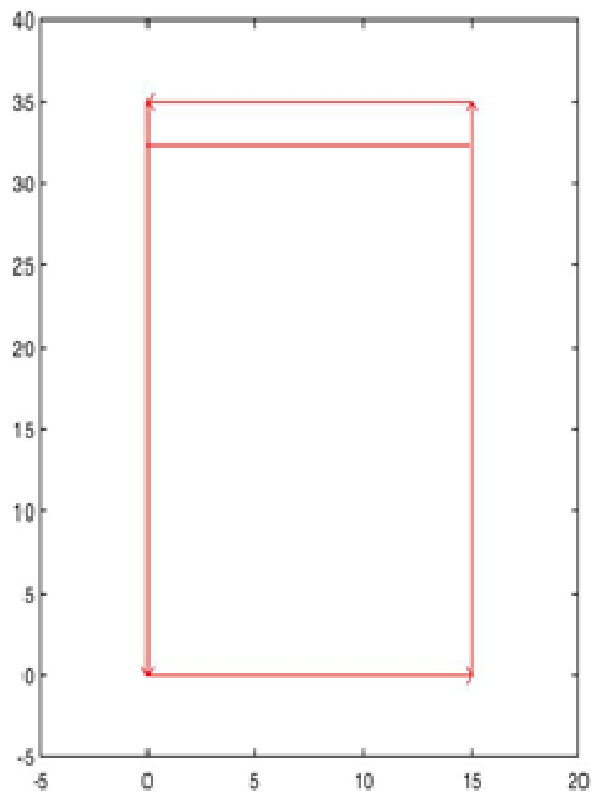

Fig. 4. Boundary conditions of the investigated object

\section{Experimental Results}

The solution of the problem is considered in a stationary mode, taking into account the temperature of phase transformation from solid to liquid state of the two elements $\mathrm{Fe}-\mathrm{Cu}$. In this case the copper has a lower phase transformation temperature and its particles will melt first, as opposed to iron.

The figures 5, 6 and 7 illustrate the different topologies, observed in the simulation as a function of the initial materials composition. They show the temperature distribution and the evolution of the solid-liquid interface during the formation of the composite structure with an increase in the number of iterations. Phase field simulation illustrates the formation of a topologically connected continuous structure after melting and infiltration of the melt (Cu-matrix). The 2D simulation results show that the concentration of Fe elements in the liquid part (Cu melt) in the upper part of the sample is controlled by the steady state. The iron stays stable and affects the concentration of $\mathrm{Cu}$ in the liquid side on the top of the sample (Figure 5.b). The solid phase ( $\mathrm{Fe})$ and the liquid phase $(\mathrm{Cu}$ melt) are moving until equilibrium is achieved between them (Figure 7.b). 


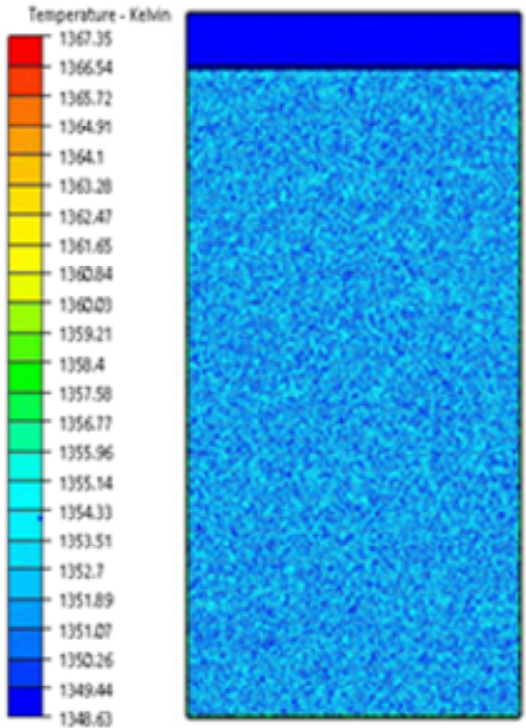

a)

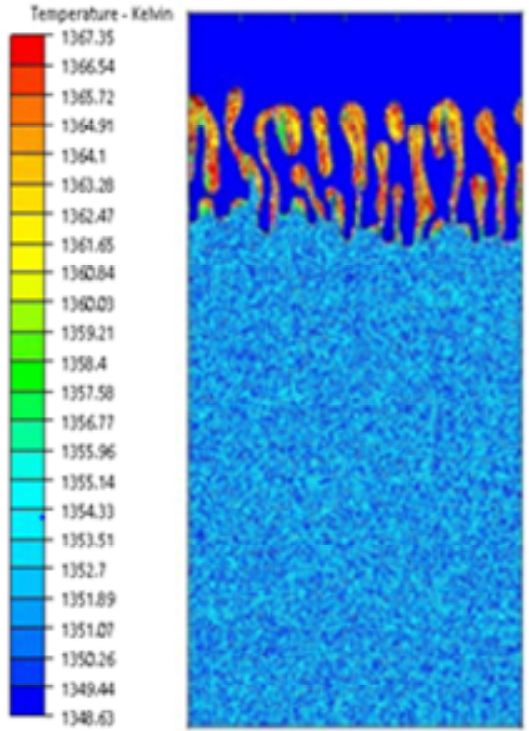

b)

Fig. 5. Solution of the task at 0 iteration (a) and 30 iteration (b)

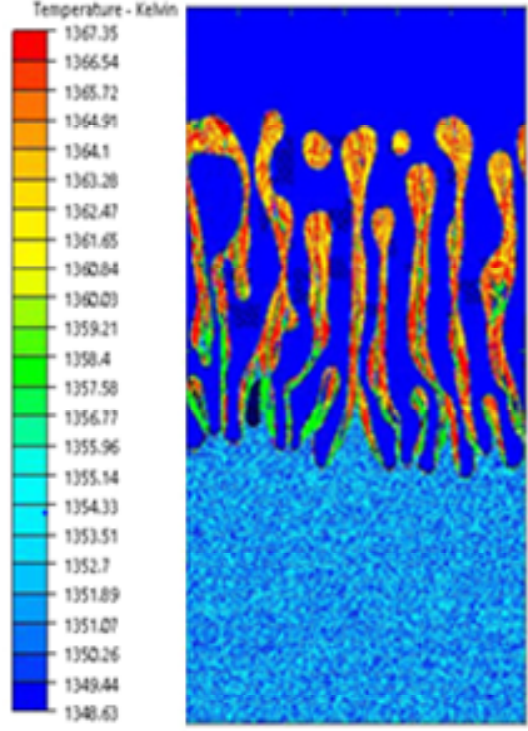

a)

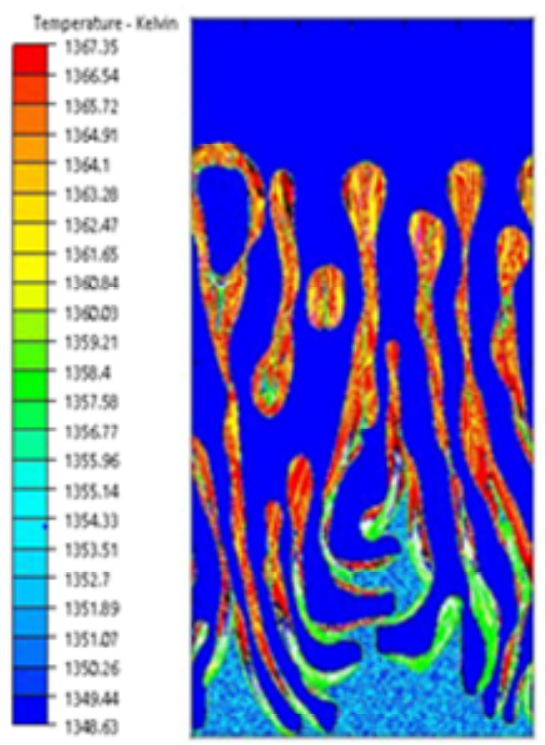

b)

Fig. 6. Solution of the task at 60 iteration (a) and 90 iteration (b) 


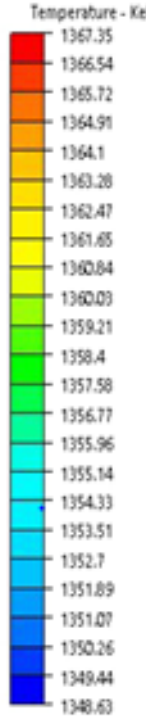

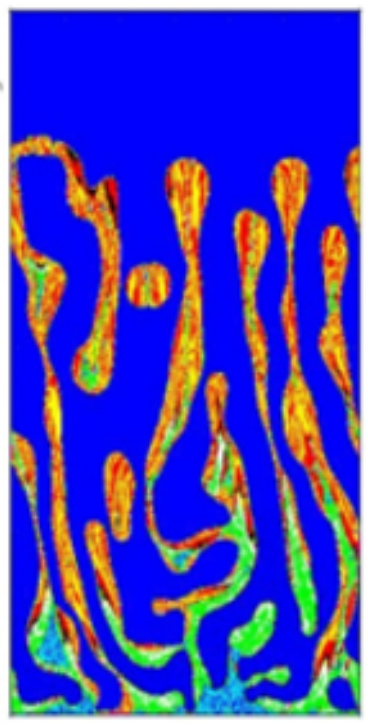

a)

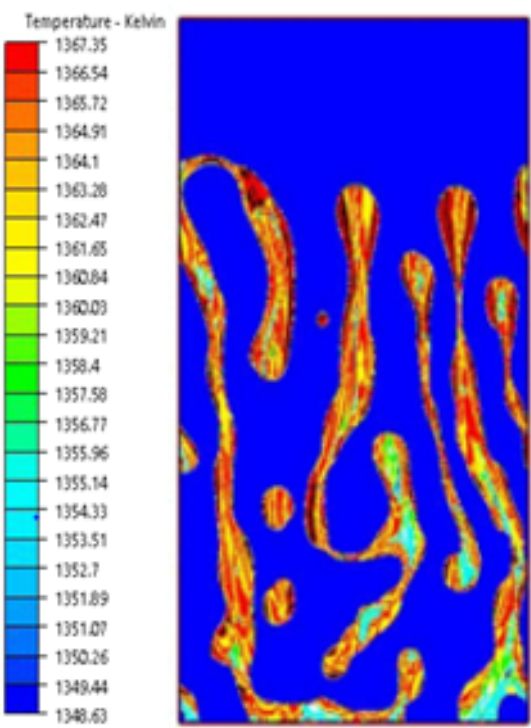

b)

Fig. 7. Solution of the task at 120 iteration (a) and 150 iteration (b)

\section{Conclusion}

After the conducted investigation, based on the results obtained, the following more important conclusions can be drawn:

1.The use of a mesoscale phase field to form a mathematical model has been demonstrated during the production of a complex relief MMCs by the capillary molding method.

2. Based on the measured temperatures during the production of a complex relief MMCs, a mathematical model of the behavior of the liquid phase $(\mathrm{Cu}$ melt) relative to the reinforcement phase $(\mathrm{Fe})$ has been made.

3. A simulation was created, which clarifies the temperature fields and the causal liaison between the matrix and the reinforcement phase at the time of obtaining the complex relief MMC by the capillary molding method.

4. The liquid metal in the obtaining of complex relief MMCs by the capillary molding method is emerging as a new technology for the production of a topological complex of metal- composite structures with ultra-high interfacial area and other unique qualities.

5. The mathematical model, that was generated, provides the possibility of clarifying the interaction between the liquid and the solid phase, based on the temperature field, thus furthermore to technology contribute to the expected wetting on the reinforcement phase.

\section{References}

Зиновьев, В. Е. (1989). Теплофизические свойства металлов при высоких температурах. Справочник. Металлургия., с.34 (in Russian)

Марков И. „Метод на крайните елементи“, София 2014 - с. 67-69 (in Bulgarian)

Марков, К. 3. (2002). Математическо моделиране. Университетско издателство" Св. Климент Охридски", с. 43-44. (in Bulgarian)

Радев Р.Й., Спасова Д.Т., Атанасов Н.М., Иванова Р.И., (2010)., „Метод за изработване на леярски форми“" Патент BG 65955 B1 (in Bulgarian) 
Шубина, М. В., Вдовин, К. Н., Девятов, Д. Х., \& Гималетдинов, Р. Х. (2011). Математическое моделирование процесса формирования отливки с учетом фазовых превращений и диффузионных явлений. Теория и технология металлургического производства, (11). (in Russian)

Daniel B., John R., 1976 "Diffusion in Copper and Copper Alloys Part IV. Diffusion in Systems Involving Elemenst of Group VIII", Metallurgy Division, Institute for Materials Research, National Bureau of Standards, Washington, p. 1321

Butrymowicz, D. B., Manning, J. R., \& Read, M. E. (1976). Diffusion in copper and copper alloys part IV. Diffusion in systems involving elements of group VIII. Journal of Physical and Chemical Reference Data, 5(1), 103-200. doi:10.1063/1.555528

Geslin, P.-A., McCue, I., Gaskey, B., Erlebacher, J., \& Karma, A. (2015). Topology-generating interfacial pattern formation during liquid metal dealloying. Nature Communications, 6(1). doi: $10.1038 /$ ncomms 9887

Klein, S., Weber, S. \& Theisen, W. J Mater Sci (2015) 50: 3586. https://doi.org/10.1007/s10853-0158919-y

Markov I., 2002 "Computer Implementation of Equivalent Nodal Forces for Timoshenko Plane Frame Element”, 1'Universite d'Architecture, de Genie Civil et de Geodesie- Sofia, vol. XL, fasc. VI, p.174-176.

Wang, H., Xu, Y., Shimono, M., Tanaka, Y., \& Yamazaki, M. (2007). Computation of Interfacial Thermal Resistance by Phonon Diffuse Mismatch Model. MATERIALS TRANSACTIONS, 48(9), 2349-2352. doi:10.2320/matertrans.maw200717 